\title{
ASSOCIAÇÃO DE TURFA E DE NITROGÊNIO EM COBERTURA NA PRODUTIVIDADE DO MILHO
}

Francisco Fábio Albuquerque Mota1; Yweenns Teixeira Ferraz ${ }^{1}$; Daiane de Cinque Mariano $^{2}$; Cândido Ferreira de Oliveira Neto ${ }^{3}$; Ricardo Shigueru Okumura²

${ }^{1}$ Discentes do curso de Agronomia da Universidade Federal Rural da Amazônia, Campus Capitão Poço, Capitão Poço/PA - Brasil.

${ }^{2}$ Professor(a) Adjunto da Universidade Federal Rural da Amazônia, Rodovia PA 275 km 7, Campus Parauapebas, Parauapebas/PA - Brasil, Bairro Cidade Nova, CEP 68515-970 (ricardo.okumura@ufra.edu.br).

${ }^{3}$ Professor Adjunto da Universidade Federal Rural da Amazônia, Instituto de Ciências Agrárias, Belém/PA - Brasil.

Recebido em: 08/04/2017 - Aprovado em: 10/06/2017 - Publicado em: 20/06/2017 DOI: 10.18677/EnciBio_2017A16

Fertilizantes nitrogenados, quando disponibilizados ao solo, podem sofrer processos de lixiviação, fixação no solo e, principalmente volatilização, uma alternativa para minimizar as perdas da aplicação de ureia pode ser a associação com a turfa fértil. Nesse sentido, o objetivo do estudo foi avaliar as combinações de turfa fértil e fertilizante nitrogenado no desenvolvimento da cultura do milho na região de Capitão Poço - Pará. O experimento foi conduzido em condições de campo, no município de Capitão Poço. O delineamento experimental adotado foi o de blocos ao acaso, com quatro repetições. O experimento foi constituído com quatro tratamentos, assim especificado: T1: NPK; T2: NPK + nitrogênio (N); T3: NPK + turfa fértil (TF); T4: NPK $+\mathrm{N}+\mathrm{TF}$. Após o florescimento pleno foi realizada a avaliação em 10 plantas de cada parcela para as seguintes variáveis: altura de planta (AP), diâmetro do colmo (DC), altura de inserção da primeira espiga (AIE) e índice de área foliar (IAF), no período da colheita, foi avaliado o comprimento das espigas (dez unidades), número de grãos por fileira, número de fileiras de grãos, diâmetro da espiga, massa de mil grãos e produtividade de grãos. A produtividade de grãos apresentaram diferenças estatísticas, em que o tratamento T4 (NPK $+\mathrm{N}+$ Turfa fértil) foi superior comparativamente aos tratamentos T1, T2 e T3, com valor de $3899,93 \mathrm{~kg} \mathrm{ha}^{-1}$. O tratamento T2 (3261,98 kg ha-1) e T3 $\left(3261,52 \mathrm{~kg} \mathrm{ha}^{-1}\right)$ foram iguais estatisticamente, e superiores a produtividade de grãos obtido no tratamento T1 $\left(2537,53 \mathrm{~kg} \mathrm{ha}^{-1}\right)$. O tratamento NPK $+\mathrm{N}+$ Turfa fértil promove o maior desenvolvimento na altura de planta $(151,28 \mathrm{~cm})$, altura de espiga $(45,46 \mathrm{~cm})$, e produtividade de grãos $(3899,93 \mathrm{~kg}$ ha $^{-1}$ ) no milho cultivado na região de Capitão Poço.

PALAVRA-CHAVE: produtividade de grãos, substâncias húmicas, Zea mays, 


\title{
ASSOCIATION OF PEAT AND SIDEDRESSING NITROGEN ON CORN YIELD
}

\begin{abstract}
The aims of study were to evaluate association of peat and nitrogen fertilizer on corn development in Capitão Poço city, State of Pará, Brazil. The experiment was conducted in field conditions in Capitão Poço city. The experimental design was a randomized complete block design, with four replications. Experiment consisted of four treatments: T1: NPK; T2: NPK + nitrogen (N); T3: NPK + turfa fértil (TF); T4: $\mathrm{NPK}+\mathrm{N}+\mathrm{TF}$. After corn flowering, 10 plants of each plot were evaluated for following variables: plant height, stem diameter, ear height and index of leaf area, on harvest period were evaluated ear length (ten units), number of grains per row, number of rows of grains, ear diameter, thousand grain mass and grain yield. Grain productivity showed statistical differences, in which T4 treatment (NPK + N + Turfa fértil) was higher than T1, T2, and T3 treatments, with a value of $3899.93 \mathrm{~kg} \mathrm{ha}^{-1}$. T2 $\left(3261.98 \mathrm{~kg} \mathrm{ha}^{-1}\right)$ and T3 $\left(3261.52 \mathrm{~kg} \mathrm{ha}^{-1}\right)$ treatment were statistically similar, and higher than the grain yield obtained in T1 treatment $\left(2537.53 \mathrm{~kg} \mathrm{ha}^{-1}\right)$. NPK $+\mathrm{N}+$ Turfa fértil treatment promotes the greatest development at plant height $(151.28 \mathrm{~cm})$, ear height $(45.46 \mathrm{~cm})$, and grain yield $\left(3899.93 \mathrm{~kg} \mathrm{ha}^{-1}\right)$ on corn grown in Capitão Poço region.
\end{abstract}

KEYWORDS: humic substances, Zea mays, grain yield

\section{INTRODUÇÃO}

A disponibilidade de $\mathrm{N}$ no solo ocorre, basicamente, pela mineralização da matéria orgânica e por aplicações de adubos nitrogenados. Logo, para o aumento da produtividade de grãos de milho tem sido necessário adotar técnicas como a adubação nitrogenada (OKUMURA et al., 2013; NAKAO et al., 2014), principalmente com a aplicação de ureia em cobertura na camada superficial do solo (DA ROS et al., 2015).

Fertilizantes industriais (sintéticos), quando disponibilizados ao solo, podem sofrer processos de lixiviação, fixação no solo e, principalmente por volatilização (NASCIMENTO et al., 2013). Uma alternativa para minimizar as perdas da aplicação de ureia pode ser a associação com substâncias húmicas, com resultados positivos descritos por CANELLAS et al. (2013). No entanto, deve ter cautela nas recomendações, pois existe poucas informações a respeito do mecanismo em que os ácidos húmicos auxiliam na melhoria da eficiência na utilização do N-ureia.

Os benefícios das substâncias húmicas nas plantas são o incremento no desenvolvimento de raízes laterais (AGUIAR et al., 2013), ativação das bombas de prótons $\mathrm{H}+$-ATPases presentes na membrana plasmática das células radiculares (BALDOTTO \& BALDOTTO, 2014). Enquanto, no solo as substâncias húmicas apresentam funções como regulação na disponibilidade de $\mathrm{NH}_{3}$ gerada na hidrólise da ureia (DONG et al., 2009).

O fertilizante orgânico se comparado com o químico apresenta favorecimento e multiplicação de microrganismos benéficos, que por sua vez proporcionam atividade microbiana e sanidade do solo, o que promove maior porosidade no solo, assim aeração nas camadas profundas e melhor desenvolvimento do sistema radicular (IZUMI et al., 2010).

Os adubos orgânicos são uma alternativa para os pequenos produtores rurais, por reduzirem os custos e pela acessibilidade nas condições técnicoeconômicas da propriedade agrícola (SILVA et al., 2012). Nesse sentido, o objetivo 
do estudo foi avaliar as combinações de turfa fértil e fertilizante nitrogenado no desenvolvimento da cultura do milho na região de Capitão Poço - Pará.

\section{MATERIAL E MÉTODOS}

O experimento foi conduzido em condições de campo, no município de Capitão Poço (S1 44' 47'W 470 03' 57'), região Nordeste do Estado do Pará (Figura 1). O clima segundo a classificação de Köppen é do tipo Ami caraterizado por apresentar elevado índice pluviométrico anual, com pequeno período seco, em que pelo menos um mês pode apresentar índice pluviométrico inferior a $60 \mathrm{~mm}$ (MENEZES et al., 2015), sendo os dados de precipitação pluvial no período experimental apresentados na Figura 2, obtidas na estação meteorológica da Universidade Federal Rural da Amazônia Campus de Capitão Poço.

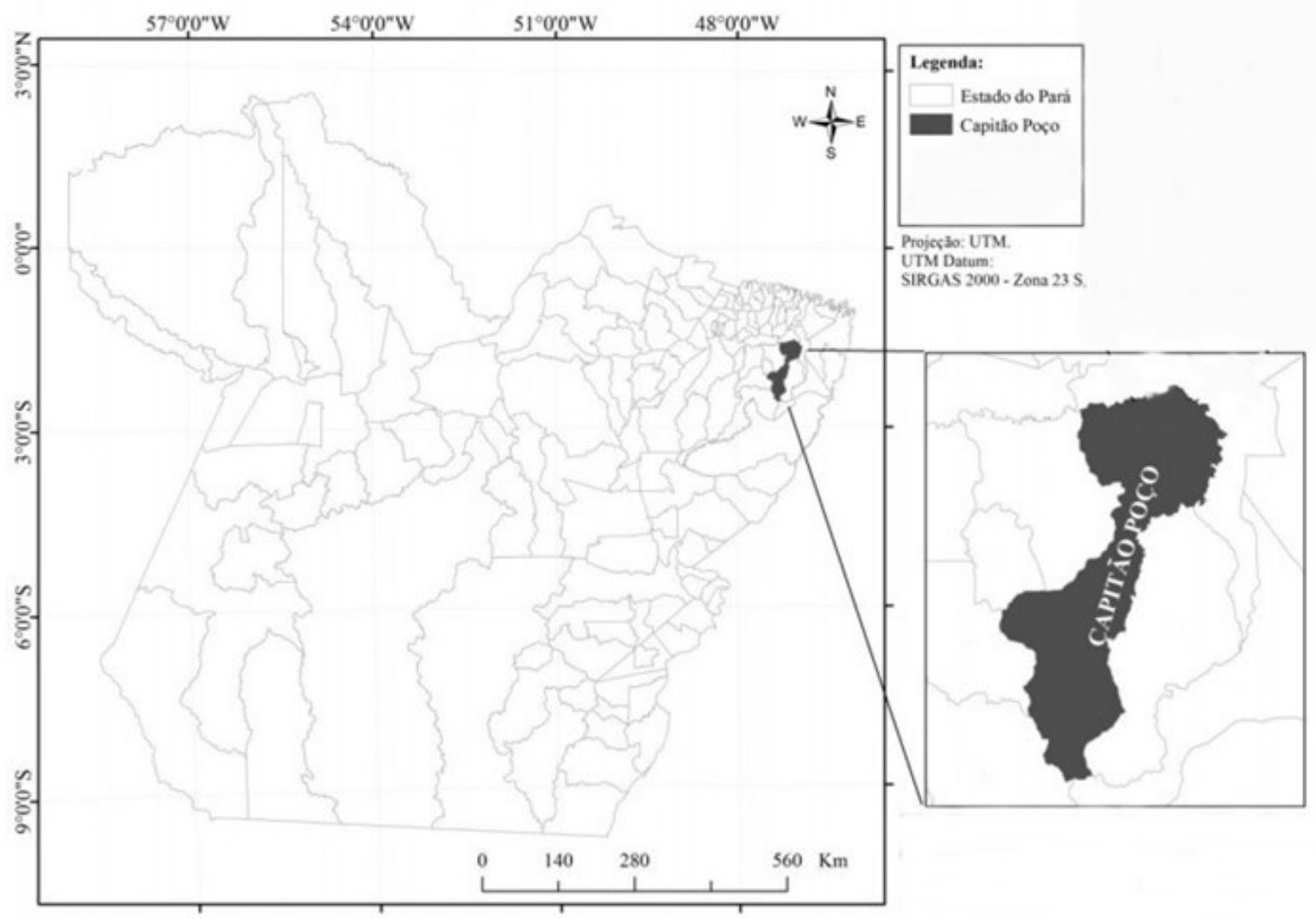

FIGURA 1. Localização do município de Capitão Poço - PA. 


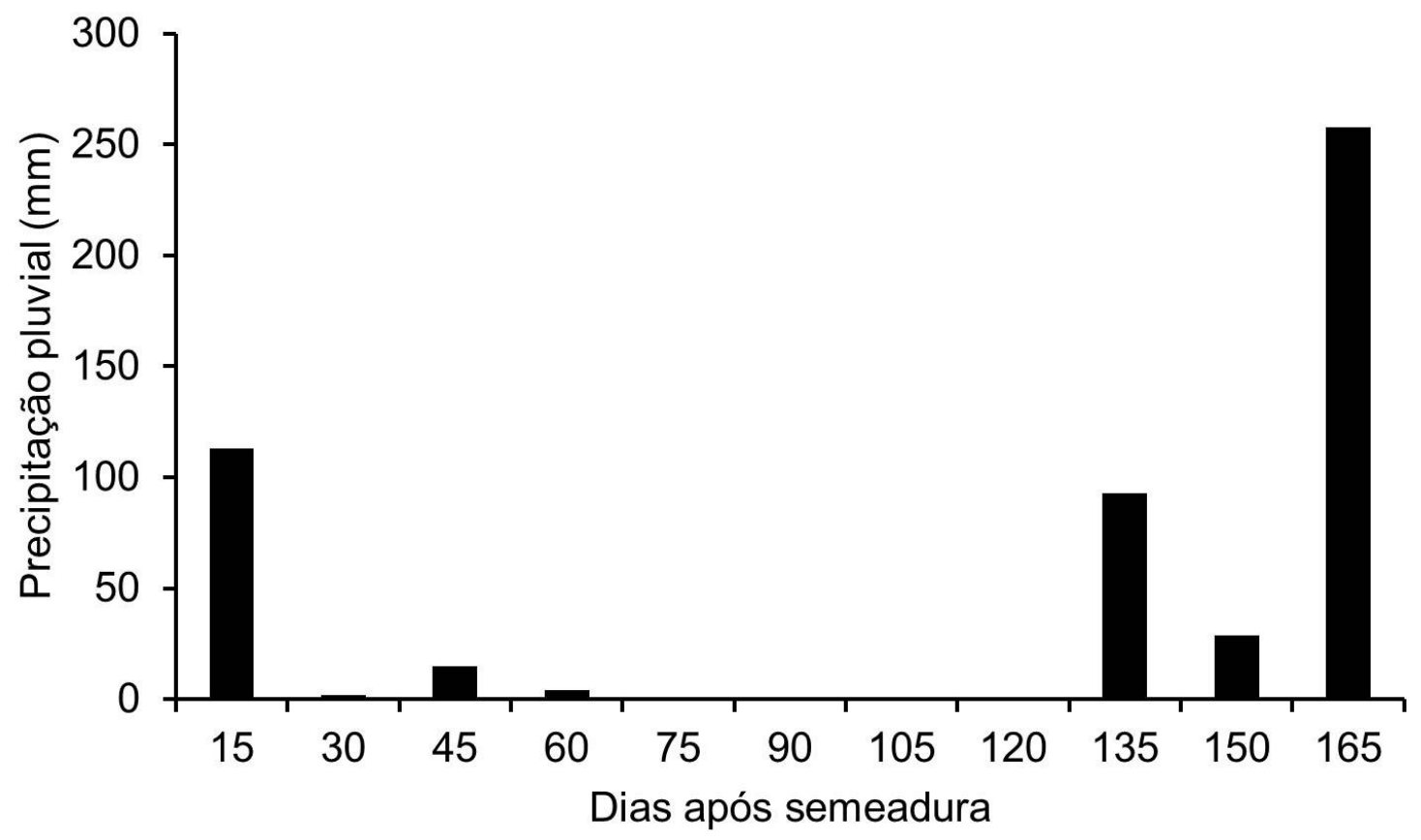

FIGURA 2. Precipitações pluviais ocorridas durante o período experimental.

A implantação do experimento ocorreu após preparo do solo no dia 17 de Janeiro de 2015, sendo realizada a semeadura do milho cultivar AL Bandeirante no dia 20 de janeiro, por meio de plantadora manual (matraca) e adubação em sulco de semeadura com $333 \mathrm{~kg} \mathrm{ha}^{-1}$ de NPK na formulação 04-20-20, baseada nas recomendações de adubação e calagem para o Estado do Pará (CRAVO et al., 2010). O delineamento experimental adotado foi o de blocos ao acaso, com quatro repetições e quatro tratamentos (Tabela 1 ).

TABELA 1. Descrição dos tratamentos utilizados durante o experimento.

\begin{tabular}{cc}
\hline Tratamento & Descrição \\
\hline T1: NPK & Sem adubação em cobertura \\
T2: NPK + nitrogênio (N) & $100 \mathrm{~kg} \mathrm{ha}^{-1} \mathrm{de} \mathrm{N} \mathrm{(fonte} \mathrm{ureia)} \mathrm{em} \mathrm{cobertura} \mathrm{no} \mathrm{estádio} \mathrm{fenológico} \mathrm{V}_{4}$ \\
T3: NPK + turfa fértil (TF) & 10 litros ha $^{-1}$ de Titanium FH $\left(\mathrm{N}\right.$ total- $1.478 \mathrm{mg} \mathrm{kg}^{-1}$ ) na semeadura \\
T4: NPK + N + TF & 10 litros ha-1 de Titanium FH semeadura $+100 \mathrm{~kg} \mathrm{ha}^{-1}$ de N cobertura \\
\hline
\end{tabular}

A aplicação do Titanium $\mathrm{FH}$ foi realizada nas linhas de plantio por meio de um regador na quantidade equivalente a 10 litros ha-1 ${ }^{-1}$ logo após a semeadura do milho. Para a adubação de $\mathrm{N}$ em cobertura foi realizada manualmente, a lanço, utilizando uréia na dose de $100 \mathrm{~kg} \mathrm{ha}^{-1}$ de $\mathrm{N}$, aplicado aproximadamente $0,08 \mathrm{~m}$ distante das fileiras de plantas quando estas se apresentaram nos estádios fenológico $V_{4}$.

Cada parcela experimental foi constituída por 4 linhas de semeadura de $3,0 \mathrm{~m}$ de comprimento, com espaçamento de $0,90 \mathrm{~m} \times 0,20 \mathrm{~m}$ entre linhas e na linha, respectivamente. Os tratos culturais e fitossanitários realizados nos experimentos foram àqueles comuns à cultura do milho. Inicialmente, o controle de plantas daninhas foi realizado por meio da dessecação, e mediante a aplicação em pósemergência do herbicida Glifosato na dosagem de 6,5 $\mathrm{L} \mathrm{ha}^{-1}$, associado à realização de capinas manual quando necessário.

Após o florescimento pleno foi realizada a avaliação em 10 plantas de cada parcela para as seguintes variáveis: altura de planta (AP), diâmetro do colmo (DC), 
altura de inserção da primeira espiga (AIE) e índice de área foliar (IAF), por meio de uma fita métrica e um paquímetro.

A avaliação da altura das plantas foi efetuada por meio da mensuração do comprimento do colmo (da superfície do solo até a base da inflorescência masculina), sendo avaliadas dez plantas por parcela (PRICINOTTO et al., 2014). O diâmetro de colmo foi determinado em dez plantas de cada unidade experimental, usando-se paquímetro digital a $5 \mathrm{~cm}$ da superfície do solo. $\mathrm{E}$ a altura de inserção da primeira espiga foi obtida pela mensuração da base inferior da planta (colo) até a inserção da primeira espiga com a utilização de uma fita métrica (LIMA et al., 2014).

$\mathrm{Na}$ determinação da área foliar (AF) foram avaliadas cinco plantas de cada parcela experimental, das quais foram mensurados o comprimento (C) e a largura (L), na parte mediana de todas as folhas de cada uma das plantas, para a obtenção inicial da área foliar (AF). $\mathrm{O}$ cálculo da área foliar foi feito mediante emprego da seguinte equação: $\operatorname{AF}\left(\mathrm{m}^{2}\right)=0,75{ }^{*} \mathrm{C}$ * $\mathrm{L}$. Posteriormente, foram somados os valores individuais de todas as folhas para obter o valor total de área foliar por planta da unidade experimental. Assim, o índice de área foliar foi calculado a partir das medidas de área foliar, utilizando a seguinte equação: IAF $=A F /\left(e_{1}{ }^{*} e_{2}\right)$, em que $e_{1}$ $\mathrm{e}_{2}$ referem-se ao espaçamento entre plantas na linha de plantio $(\mathrm{m})$ e entre as linhas de plantio $(\mathrm{m})$, respectivamente (SANGOI et al., 2007).

No período da colheita, foi avaliado o comprimento das espigas (dez unidades) em cada parcela de tratamento, utilizando uma régua de $30 \mathrm{~cm}$. Com as mesmas espigas foi mensurado o número de grãos por fileira, por meio da contagem simples dos grãos presentes em uma fileira de cada espiga (OKUMURA et al., 2014). O número de fileiras de grãos foi determinado através da contagem simples dos números de fileiras presentes em uma espiga, nas mesmas avaliadas. Após a colheita, mensurou-se o diâmetro da espiga na parte mediana ou ponto médio das 10 espigas com utilização de um paquímetro digital.

A colheita foi realizada manualmente, no período de maturação fisiológica do milho, com posterior trilhagem, pesagem dos grãos, determinação do teor de umidade, e os resultados transformados em kg ha-1 (13\% de base úmida) (ASSIS et al., 2013). A massa de mil grãos foi determinada mediante contagem simples de 100 grãos por parcela, com 5 repetições, e pesados em balança analítica, e convertidos para massa de mil grãos (CARVALHO et al., 2014).

Inicialmente, os dados experimentais foram submetidos aos testes de Shapiro-Wilks e de Levene $(p>0,01)$, para verificação da normalidade e homocedasticidade residuais, respectivamente. Posteriormente, atendidas as pressuposições básicas os dados experimentais foram submetidos ao teste de análise de variância e as médias dos tratamentos comparadas pelo teste de Tukey, a 5\% de probabilidade, utilizando o software estatístico SISVAR (FERREIRA, 2011).

\section{RESULTADOS E DISCUSSÃO}

De acordo com a análise de variância as variáveis apresentaram diferença significativa a 5 e $1 \%$ de probabilidade ao teste $F$ (Tabelas 2,3 e 4), indicando diferenças nos tratamentos. Para os valores de CV (\%), de maneira geral, apresentaram baixos valores (inferiores a 20\%), demonstrando confiabilidade na homogeneidade dos valores médios e boa precisão experimental. Os coeficientes de variação obtidos no presente estudo enquadram-se no intervalo de CV classificado como intermediário por FRITSCHE-NETO et al. (2012). 
TABELA 2. Análise de variância para altura de planta (AP), altura de espiga ( $A E)$, diâmetro do colmo (DC) e índice de área foliar (IAF) do híbrido de milho (AL-Bandeirante) submetido a associação de turfa fértil e de nitrogênio em cobertura no município de Capitão Poço, PA.

\begin{tabular}{lccccc}
\hline FV & GL & \multicolumn{4}{c}{ Quadrados Médios } \\
\cline { 3 - 6 } & & $\mathrm{AP}$ & $\mathrm{AE}$ & $\mathrm{DC}$ & $\mathrm{IAF}$ \\
\hline Tratamento & 3 & $570,83^{\text {** }}$ & $219,75^{\text {** }}$ & $12,86^{*}$ & $0,094^{\text {ns }}$ \\
Bloco & 3 & $188,58^{\text {ns }}$ & $18,00^{\text {ns }}$ & $6926,66^{\text {ns }}$ & $0,11^{\text {ns }}$ \\
Resíduo & 9 & 60804,08 & 4941,48 & 2538,51 & 0,03 \\
\hline CV $\%$ ) & & 5,78 & 6,28 & 9,63 & 16,35 \\
\hline Média geral & & 134,92 & 35,41 & 16,55 & 1,08 \\
\hline
\end{tabular}

**; *; ns: significativo a 1\%, significativo a $5 \%$ e não significativo, respectivamente, pelo teste $F$.

TABELA 3. Análise de variância para comprimento de espiga (CE), diâmetro de espiga (DE), número de fileiras (NF) e número de grãos por fileira (NGF) do híbrido de milho (AL-Bandeirante) submetido a associação de turfa fértil e de nitrogênio em cobertura no município de Capitão Poço, PA.

\begin{tabular}{|c|c|c|c|c|c|}
\hline \multirow[t]{2}{*}{ FV } & \multirow[t]{2}{*}{ GL } & \multicolumn{4}{|c|}{ Quadrados Médios } \\
\hline & & $\mathrm{CE}$ & $\mathrm{DE}$ & $\mathrm{NF}$ & NGF \\
\hline Tratamento & 3 & $3,13^{\text {t* }}$ & $0,06^{* *}$ & $0,22^{\text {ns }}$ & $10,32^{*}$ \\
\hline Bloco & 3 & $0,22^{\text {ns }}$ & $0,01^{\text {ns }}$ & $0,09^{\text {ns }}$ & $0,22^{\text {ns }}$ \\
\hline Resíduo & 9 & 0,06 & 0,01 & 0,67 & 0,85 \\
\hline CV (\%) & & 2,01 & 1,84 & 6,27 & 4,10 \\
\hline Média geral & & 12,45 & 3,66 & 13,07 & 22,58 \\
\hline
\end{tabular}

**; *; ns: significativo a 1\%, significativo a $5 \%$ e não significativo, respectivamente, pelo teste $F$.

TABELA 4. Análise de variância para massa de mil grãos (MMG) e produtividade de grãos (PROD) do híbrido de milho (AL-Bandeirante) submetido a associação de turfa fértil e de nitrogênio em cobertura no município de Capitão Poço, PA.

\begin{tabular}{|c|c|c|c|}
\hline \multirow[t]{2}{*}{ FV } & \multirow{2}{*}{$\mathrm{GL}$} & \multicolumn{2}{|c|}{ Quadrados Médios } \\
\hline & & MMG & PROD \\
\hline Tratamento & 3 & $2449,42^{* *}$ & $1239886,43^{* *}$ \\
\hline Bloco & 3 & $43,43^{\text {ns }}$ & $28160,31^{\text {ns }}$ \\
\hline Resíduo & 9 & 38146,43 & 35798915,25 \\
\hline CV (\%) & & 2,44 & 5,84 \\
\hline Média gera & & 252,77 & 3240,24 \\
\hline
\end{tabular}

A altura de planta (AP) apresentou os maiores valores de 135,93 e 151,28 cm nos tratamento T3 e T4, respectivamente (Tabela 5), o que demonstra que a aplicação da turfa fértil foi suficiente para proporcionar adequadamente os nutrientes para o crescimento vegetativo do milho. De acordo com ENSINAS et al. (2011) e BONINI et al. (2015) os ganhos dos fertilizantes orgânicos no solo são na disponibilidade de nutrientes, teor de nutrientes, capacidade de troca de cátions, areação, retenção de umidade, boa agregação às raízes e incremento da matéria orgânica do solo. 
TABELA 5. Altura de planta (AP), altura de espiga (AE), diâmetro do colmo (DC) e índice de área foliar (IAF) do híbrido de milho (AL-Bandeirante) submetido a associação de turfa fértil e de nitrogênio em cobertura no município de Capitão Poço, PA.

\begin{tabular}{|c|c|c|c|c|}
\hline Tratamento & $\mathrm{AP}$ & $\mathrm{AE}$ & $\mathrm{DC}$ & $\mathrm{IAF}$ \\
\hline T1: NPK & $128.33 b^{*}$ & $31.66 \mathrm{bc}$ & $\begin{array}{c}\mathrm{mm} \\
15.13 \mathrm{~b}\end{array}$ & 109 \\
\hline T2: NPK + N & $124,14 b$ & $28,40 c$ & $15,13 \mathrm{~b}$ & $0,86 a$ \\
\hline T3: NPK + TF & $135,93 a b$ & $36,13 b$ & $17,06 a b$ & $1,16 a$ \\
\hline T4: NPK + N + TF & $151,28 a$ & $45,46 a$ & $18,86 a$ & $1,20 a$ \\
\hline
\end{tabular}

* médias seguidas de mesma letra, não diferem pelo teste de Tukey a $5 \%$ de probabilidade.

Para a variável altura da espiga (AE) o tratamento T4 obteve valor de 45,46 $\mathrm{cm}$, superior comparativamente aos tratamentos $\mathrm{T} 1$ e T2, nas quais apresentaram altura da espiga de 31,66 e $28,40 \mathrm{~cm}$, respectivamente (Tabela 5). Com relação a variável diâmetro do colmo os tratamentos T3 e T4 foram os que promoveram maiores valores de 17,06 e 18,86 mm, respectivamente (Tabela 5). A importância do colmo na planta se deve por atuar como estrutura de armazenamento de sólidos solúveis que serão translocados, posteriormente, para o enchimento dos grãos (MARÓSTICA \& FEIJÓ, 2013).

$O$ índice de área foliar (IAF) não apresentou diferença significativa para os tratamentos aplicados no presente estudo, devido a cultura no início do processo de crescimento apresentar baixa taxa de crescimento (PEIXOTO et al., 2011), e com isso a absorção de água e nutrientes é relativamente baixo, assim a reserva energética das sementes pode ter promovido a suplementação da demanda nutricional do milho para iniciar a formação dos diferentes órgãos componentes.

O tratamento T4 apresentou o melhor desempenho para a variável comprimento da espiga, com valor de $13,73 \mathrm{~cm}$ (Tabela 6). SANTOS et al. (2014) verificaram que o comprimento da espiga, não apresentou diferença significativa entre adubação química e orgânica, com média de $24 \mathrm{~cm}$, indicando que, independente do tipo de adubo, são capazes de promover o desenvolvimento das espigas de milho.

TABELA 6. Comprimento de espiga (CE), diâmetro de espiga (DE) e número de fileiras (NF) do híbrido de milho (AL-Bandeirante) submetido a associação de turfa fértil e de nitrogênio em cobertura no município de Capitão Poço, PA.

\begin{tabular}{lccc}
\hline Tratamento & $\mathrm{CE}$ & $\mathrm{DE}$ & $\mathrm{NF}$ \\
\hline T1: NPK & $11,85 \mathrm{~b}^{*}$ & $3,49 \mathrm{~b}$ & $13,07 \mathrm{a}$ \\
T2: NPK + N & $11,87 \mathrm{~b}$ & $3,74 \mathrm{a}$ & $13,40 \mathrm{a}$ \\
T3: NPK + TF & $12,36 \mathrm{~b}$ & $3,64 \mathrm{ab}$ & $12,93 \mathrm{a}$ \\
T4: NPK + N + TF & $13,73 \mathrm{a}$ & $3,77 \mathrm{a}$ & $12,87 \mathrm{a}$ \\
\hline
\end{tabular}

${ }^{*}$ médias seguidas de mesma letra, não difere do teste de Tukey a $5 \%$ de probabilidade.

No presente trabalho, o diâmetro da espiga obteve os melhores resultados nos tratamentos T2 $(3,74 \mathrm{~cm})$, T3 $(3,64 \mathrm{~cm})$ e T4 $(3,77 \mathrm{~cm})$, enquanto para o número de fileiras não foram observadas diferenças estatísticas entre os tratamentos (Tabela 6). Resultados semelhantes são descritos por SANTOS et al. (2014) que 
obtiveram efeito significativo no diâmetro da espiga (DE) e não observaram diferença significativa no número de fileiras (NF).

Para o número de grãos por fileira o tratamento T4 (NPK + N + Turfa fértil) proporcionou o maior valor $(24,80)$, apresentando maior incremento comparativamente aos tratamentos T1 (NPK), T2 (NPK + N) e T3 (NPK + Turfa fértil) (Tabela 7).

TABELA 7. Número de grãos por fileira (NGF), massa de mil grãos (MMG) e produtividade de grãos (PROD) do híbrido de milho (AL-Bandeirante) submetido a associação de turfa fértil e de nitrogênio em cobertura no município de Capitão Poço, PA.

\begin{tabular}{lccc}
\hline Tratamento & NGF & MMG & PROD \\
\hline T1: NPK & $21,73 b^{*}$ & $\mathrm{~g}$ & $\mathrm{~kg} \mathrm{ha}^{-1}$ \\
T2: NPK + N & $21,13 \mathrm{~b}$ & $225,21 \mathrm{c}$ & $2537,53 \mathrm{c}$ \\
T3: NPK + TF & $22,67 \mathrm{~b}$ & $250,07 \mathrm{~b}$ & $3261,98 \mathrm{~b}$ \\
T4: NPK + N + TF & $24,80 \mathrm{a}$ & $250,40 \mathrm{~b}$ & $3261,52 \mathrm{~b}$ \\
\hline
\end{tabular}

* médias seguidas de mesma letra, não difere do teste de Tukey a $5 \%$ de probabilidade.

Com relação a variável massa de mil grãos (MMG), o tratamento T4 (NPK + N + Turfa fértil) proporcionou o melhor desempenho (285,39 g) (Tabela 7). A matéria orgânica atuou na melhoria das propriedades físico-químicas do solo (ENSINAS et al., 2011; BONINI et al., 2015), assim, proporcionando maior retenção dos nutrientes e diminuição das perdas de $\mathrm{N}$ no solo, e associado ao NPK resultaram positivamente no incremento da MMG.

Os tratamentos T2 (NPK + N) e T3 (NPK + Turfa fértil) apresentaram resultados iguais estatisticamente para a MMG, sendo inferior aos obtidos no tratamento T4 (NPK + N + Turfa fértil). A aplicação de fertilizante nitrogenado associado com a turfa fértil obtiveram resultados superiores comparativamente a aplicação isolada de NPK.

Os tratamentos avaliados foram diferentes estatisticamente para a produtividade de grãos. O tratamento T2 $\left(3261,98 \mathrm{~kg} \mathrm{ha}^{-1}\right)$ e T3 $\left(3261,52 \mathrm{~kg} \mathrm{ha}^{-1}\right)$ foram iguais estatisticamente, e superiores a produtividade de grãos obtido no tratamento T1 (2537,53 kg ha-1) (Tabela 7). Os resultados obtidos pela adubação orgânica na produtividade de grãos têm apresentado valores iguais ou superiores aos descritos para a adubação química (NOVAKOWISKI et al., 2013). A utilização de fertilizantes químicos tem promovido incremento progressivo na produtividade das culturas, entretanto tem sido associado com aumento da poluição dos corpos de água e ao processo de eutrofização (RODRIGUES et al., 2011).

Assim, a adubação com turfa fértil apresenta compatibilidade para continuar proporcionando incrementos na produtividade de grãos do milho, com a manutenção dos atributos físico-químicas do solo, associado com a diminuição do custo de produção decorrente da redução na aquisição de insumos agrícolas. Para que a adubação com fertilizantes orgânicos proporcione efeitos significativos na produtividade de grãos, se faz necessário à aplicação da adubação de forma contínua por vários anos, uma vez que o efeito é maximizado a longo prazo, por meio de melhorias na fertilidade do solo, assim como promove condições físicas adequadas ao desenvolvimento do sistema radicular do milho (SILVA et al., 2008). 


\section{CONCLUSÃO}

O tratamento NPK + N + Turfa fértil promoveu o maior desenvolvimento na altura de planta $(151,28 \mathrm{~cm})$, altura de espiga $(45,46 \mathrm{~cm})$, diâmetro do colmo $(18,86 \mathrm{~mm})$, comprimento de espiga $(13,73 \mathrm{~cm})$, diâmetro de espiga $(3,77 \mathrm{~cm})$, número de grãos por fileira $(24,80)$, massa de mil grãos $(285,39 \mathrm{~g})$ e produtividade de grãos $\left(3899,93 \mathrm{~kg} \mathrm{ha}^{-1}\right)$ no milho cultivado na região de Capitão Poço.

As variáveis índice de área foliar $(1,08)$ e número de fileiras $(13,07)$ não apresentam diferenças entre os tratamentos com apenas NPK, NPK associado com $\mathrm{N}$ em cobertura, NPK associado com turfa fértil e NPK associado com $\mathrm{N}$ e turfa fértil.

\section{AGRADECIMENTOS}

Os autores agradecem ao Grupo de Estudos de Biodiversidade em Plantas Superiores da Universidade Federal Rural da Amazônia pelo apoio financeiro, concessão da área de estudo e contribuição científica dos professores.

\section{REFERÊNCIAS}

AGUIAR, N. O.; OLIVARES, F. L.; NOVOTNY, E. H.; DOBBSS, L. B.; BALMORI, D. M.; SANTOS JÚNIOR, L. G.; CHAGAS, J. G.; FAÇANHA, A. R.; CANELLAS, L. P. Bioactivity of humic acids isolated from vermicomposts at different maturation stages. Plant and Soil, v. 362, n. 1/2, p. 161-174, 2013. Disponível em: <http://dx.doi.org/10.1007/s11104-012-1277-5>. doi: 10.1007/s11104-012-1277-5

ASSIS, R. L.; OLIVEIRA, C. A. A.; PERIN, A.; SIMON, G. A.; SOUZA JUNIOR, B. A. Produção de biomassa, acúmulo de nitrogênio por plantas de cobertura e efeito na produtividade do milho safrinha. Enciclopédia Biosfera, v. 9, n. 16, p. 1769-1775, 2013.

BALDOTTO, M. A.; BALDOTTO, L. E. B. Ácidos húmicos. Revista Ceres, v. 61, suplemento, p. 856-881, 2014. Disponível em: <http://dx.doi.org/10.1590/0034737×201461000011>. doi: 10.1590/0034-737×201461000011

BONINI, C. S. B.; ALVES, M. C.; MONTANARI, R. Lodo de esgoto e adubação mineral na recuperação de atributos químicos de solo degradado. Revista Brasileira de Engenharia Agrícola e Ambiental, v. 19, n. 4, p. 388-393, 2015. Disponível em: <http://dx.doi.org/10.1590/1807-1929/agriambi.v19n4p388-393>. doi: 10.1590/1807-1929/agriambi.v19n4p388-393

CANELLAS, L. P.; MEDICI, L.; CAMPOSTRINI, E.; BALMORI, D.; MÉDICI, L.; AGUIAR, N.; FAÇANHA, A.; OLIVARES, F. A combination of humic substances and Herbaspirillum seropedicae inoculation enhances the growth of maize (Zea mays L.). Plant and Soil, v. 366, n. 1/2, p. 119-132, 2013. Disponível em: <http://dx.doi.org/10.1007/s11104-012-1382-5>. doi: 10.1007/s11104-012-1382-5

CARVALHO, I. R.; SOUZA, V. Q.; FOLLMANN, D. N.; NARDINO, M.; SCHMIDT, D. Desempenho agronômico de híbridos de milho em ambiente irrigado e sequeiro. Enciclopédia Biosfera, v. 10, n. 18, p. 1144-1153, 2014.

CRAVO, M. S.; VIÉGAS, I. J. M.; BRASIL, E. C. Recomendações de adubação e calagem para o Estado do Pará. Belém: Embrapa Amazônia Oriental, 2010. 262p. 
DA ROS, C. O.; SILVA, R. F.; BASSO, C.J.; SILVA, V. R. Nitrogênio disponível no solo e acumulado na cultura do milho associado a fontes nitrogenadas de eficiência aumentada. Enciclopédia Biosfera, v. 11, n. 21, p. 1374-1385, 2015.

DONG, L.; CORDOVA KREYLOS, A.; YANG, J.; YUAN, H.; SCOW, K. Humic acids buffer the effects of urea on soil ammonia oxidizers and potential nitrification. Soil Biology \& Biochemistry, v. 41, n. 8, p. 1612-1621, 2009.

ENSINAS, S. C.; MAEKAWA JUNIOR, M. T.; ENSINAS, B. C. Desenvolvimento de mudas de rúcula em diferentes combinações de substrato. Revista Científica Eletrônica de Agronomia, v. 18, n. 1, p. 1-7, 2011.

FERREIRA, D. F. Sisvar: A computer statistical analysis system. Ciência e Agrotecnologia, v. 35, n. 6, p. 1039-1042, 2011. Disponível em: <http://dx.doi.org/10.1590/S1413-70542011000600001>. doi: 10.1590/S141370542011000600001

FRITSCHE-NETO, R.; VIEIRA, R. A.; SCAPIM, C. A.; MIRANDA, G. V.; REZENDE, $\mathrm{L}$. M. Updating the ranking of the coefficients of variation from maize experiments. Acta Scientiarum. Agronomy, v. 34, n. 1, p. 99-101, 2012. Disponível em: $<$ http://dx.doi.org/10.4025/actasciagron.v.34i1.13115>. 10.4025/actasciagron.v.34i1.13115

IZUMI, K.; OKISHIO, Y.; NAGÃO, N.; NIWA, C.; YAMAMOTO, S.; TODA, T. Effects of particle size on anaerobic digestion of food waste. International Biodeterioration \& Biodegradation, v. 64, n. 7, p. 601-608, 2010. Disponível em: <http://dx.doi.org/10.1016/j.ibiod.2010.06.013>. doi: 10.1016/j.ibiod.2010.06.013

LIMA, J. V.; ALVES, J. D. N.; MARIANO, D. C.; ALBUQUERQUE, A. N.; OKUMURA, R. S. Comportamento agronômico de milho híbrido $B t$ submetido a diferentes densidades populacionais. Enciclopédia Biosfera, v. 10, n. 19, p. 541-549, 2014.

MARÓSTICA, L. H. B.; FEIJÓ, S. Efeito da adubação foliar no período vegetativo da cultura do milho (Zea mays). Uniciências, v. 17, n. 1, p. 37-40, 2013.

MENEZES, F. P.; FERNANDES, L. L.; ROCHA, E. J. P. O uso da estatística para regionalização da precipitação no estado do Pará, Brasil. Revista Brasileira de Climatologia, v. 16, n. 11, p. 64-71 2015. Disponível em: <http://dx.doi.org/10.5380/abclima.v16i0.40023>. doi: 10.5380/abclima.v16i0.40023

NAKAO, A. H.; DICKMANN, L.; SOUZA, M. F. P.; RODRIGUES, R. A. F.; TARSITANO, M. A. A. Análise econômica da produção de milho safrinha em função de fontes e doses de nitrogênio e inoculação com Azospirillum brasilense. Enciclopédia Biosfera, v. 10, n. 18, p. 278-290, 2014.

NASCIMENTO, C. A. C.; VITTI, G. C.; FARIA, L. A.; LUZ, P. H. C.; MENDES, F. L. Ammonia volatilization from coated urea forms. Revista Brasileira de Ciência do Solo, v. 37, n. 4, p. 1057-1063, 2013. Disponível em: <http://dx.doi.org/10.1590/S0100-06832013000400022>. doi: 10.1590/S010006832013000400022 
NOVAKOWISKI, J. H.; SANDINI, I. E.; FALBO, M. K.; MORAES, A.; NOVAKOWISKI, J. H. Adubação com cama de aviário na produção de milho orgânico em sistema de integração lavoura-pecuária. Semina: Ciências Agrárias, v. 34, n. 4, p. 1663-1672, 2013. Disponível em: <http://dx.doi.org/10.5433/1679-0359.2013v34n4p1663>. doi: 10.5433/1679-0359.2013v34n4p1663

OKUMURA, R. S.; YANO, G. T.; MARIANO, D. C.; ZACCHEO, P. V. C.; TAKAHASHI, H. W. Nutrição nitrogenada no milho fertilizado com ureia tratada com inibidor de urease. Semina: Ciências Agrárias, v. 34, n. 1, p. 157-170, 2013. Disponivel em: <http://dx.doi.org/10.5433/1679-0359.2013v34n1p157>. doi: 10.5433/1679-0359.2013v34n1p157

OKUMURA, R. S.; STRAGLIOTTO, C.; MARIANO, D. C.; LOBATO, A. K. S.; GUEDES, E. M. S.; OLIVEIRA NETO, C. F.; SALDANHA, E. C. M.; CONCEIÇÃO, H. E. O.; ALVES, G. A. R.; SILVA, R. T. L. Production componentes in transgenic $B t$ maize hybrids under different spacing. Journal of Food, Agriculture \& Environment, v. 12, n. 1, p. 255-258, 2014.

PEIXOTO, C. P.; CRUZ, T. V.; PEIXOTO, M. F. S. P. Análise quantitativa do crescimento de plantas: Conceitos e prática. Enciclopédia Biosfera, v. 7, n. 13, p. 51-76, 2011.

PRICINOTTO, L. F.; VIDIGAL FILHO, P. S.; SCAPIM, C. A.; MARQUES, O. J.; OKUMURA, R. S.; RECHE, D. L. Effects of nitrogen rates and application time on popcorn. African Journal of Agricultural Research, v. 9, n. 27, p. 2132-2141, 2014. Disponível em: <http://dx.doi.org/10.5897/AJAR2013.7471>. doi: 10.5897/AJAR2013.7471

RODRIGUES, T. R.; MAI NETO, C.; JANDREY, P. E; BERTÉ, L. N.; ANDRADE, M. G; OLIVEIRA, P. S. R. Adubação orgânica no milho como forma de melhorar a sustentabilidade do sistema de produção agrícola. Cadernos de Agroecologia, v.6, n.2, p.1-5, 2011.

SANGOI, L.; ERNANI, P. R.; SILVA, P. R. F. Maize response to nitrogen fertilization timing in two tillage systems in a soil with high organic matter. Revista Brasileira de Ciência do Solo, v. 31, n. 3, p. 507-517, 2007. Disponível em: <http://dx.doi.org/10.1590/S0100-06832007000300011>. doi: 10.1590/S010006832007000300011

SANTOS, P. R.; COSTA, K. D. S.; CARVALHO, I. D. E.; SILVA, J. P.; FERREIRA, P. V. Desempenho de genótipos de milho (Zea mays L.) submetidos a dois tipos de adubação. Revista Verde, v. 9, n. 1, p. 210-215, 2014.

SILVA, J. A.; OLIVEIRA, A. P.; ALVES, G. S.; CAVALCANTE, L. F.; OLIVEIRA, A. N. P.; ARAÚJO, M. A. M. Rendimento do inhame adubado com esterco bovino e biofertilizante no solo e na folha. Revista Brasileira de Engenharia Agrícola e Ambiental, v. 16, n. 3, p. 253-257, 2012. Disponível em: <http://dx.doi.org/10.1590/S1415-43662012000300003>. doi: 10.1590/S141543662012000300003 
SILVA, R. G.; GALVÃO, J. C. C.; MIRANDA, G. V.; SILVA, D. G.; ARNHOLD, E. Produtividade de variedades de milho nos sistemas de cultivo orgânico e convencional. Caatinga, v. 21, n. 3, p.78-85, 2008. 